Afruz M. Gurbanova

DOI: $10.25045 /$ jpis.v06.i2.10

Institute of Information Technology of ANAS, Baku, Azerbaijan

afruz@iit.ab.az

\title{
ABOUT THE TERMINOLOGY THREATS TO THE AZERBAIJANI LANGUAGE IN TERMS OF GLOBALIZATION
}

The article analyzes the "language system security" in the context of the national security, information security, freedom of language and language policy problems. The impact of ongoing globalization process on the languages, and adoption of a number of important documents on the protection of languages by the international organizations around the world is mentioned. The existing problems in the terminology of the world languages are defined and their solution ways are defined. The article focuses on the measures taken by the government towards the protection and development of the Azerbaijani language. Necessary recommendations are given on the representation of the Azerbaijani language in the virtual space and the protection of its terminology base.

Keywords: language system security, language policy, multilingual, monolingual, national terms, international terms.

\section{Introduction}

The second half of the XX century and early XXI century is characterized by high level globalization. This is related to a sharp change in the geo-political and socio-cultural situation, as well as high rates of economic development, and the progress of production and technology.

At the present stage of development of society the globalization reflects universal economic, political and cultural integration and unification processes. The opening and enlargement of borders has led to significant changes in the cultural life of the people, and the development of intercultural relations. With the acceleration of the globalization process and intercultural communication the changes occurs in the national language, as well. First of all, the changes occur in the lexical structure of the language, in particular, in the interaction of national and foreign words [1].

Protection of the language in such circumstances, preventing its lexical structure from the borrowed words is of great importance for the problem solution.

The article aims at the identification of the threats to the terminology of the Azerbaijani language in the context of globalization, and providing recommendations.

To this end, in addition to other security issues, security of the language system is analyzed from various aspects. Indicating the main dangers for the language the role of the language policy in eliminating these threats are identified.

The article analyzes the impact of the globalization process on the world's languages, a number of projects and programs realized by UNESCO for the protection of languages, and important documents adopted in this regard. The "UNESCO Atlas of the World's Languages in Danger" and the concept of "UNESCO Language Vitality and Endangerment" are the most important steps towards language protection.

The article evaluates the representation of the language in virtual space as one of the key issues in language protection, and provides their ranking on the Internet. Moreover, it highlights the measures taken by the government towards the protection of the Azerbaijani language, and analyzes usage areal of the language and a wide range of opportunities to be spread in virtual space.

Terminological activities have important missions for protection and development of the language. And terminology is constantly evolving and being updated with the scientific and technical progress. Therefore, the article highlights the recent processes going on in the world's languages, and substantiates an approach to the terminological activities from the information terminology aspect.

The article provides suggestions and recommendations on the application, development and other issues of the Azerbaijani language. 


\section{Language system security}

When we say security we mean such a circumstance of a complex system, where the functioning of internal and external factors does not affect the system performance or its deterioration or failure. Security is a protection of an individual, community, organization, and other vital interests from potential and real threats, or the absence of the threats. Various security types exist: personal security, national security, economic security, social security, political security, ecological security, information security, military security, international security and so on. Security of a language and a language system is a relatively new concept, and is not defined in scientific literature. The concept of security of a language system in many cases is conversed in the context of national security, information security, freedom of choice of language and language policy issues [2]. In academic discussions, security of a language is either an object to various threats, or a condition for security acquisition (support). In other words, along with the protection of the language, it must be protected from other types of threats.

In 2001, the lack of translators experienced in Urdu, Hindi and other languages was one of the challenges in preventing 9/11 Attack to World Trade Center in New York, US. Hence, a poor translation of the documents, which could help to prevent the terrible incident, destructed the US national security.

In 1970-1980, the irresistible prevalence of the English language in France was welcomed by the community as the threat of loss of native language and the law on the protection of the French language in 1994 (J.Toubon law) was adopted. The law obliged all English-language advertising boards to be removed from the streets of Paris, even the names of English companies to be translated into the French.

Imbalanced access of various countries (regions) to information sources or not knowing the language(s) represented on the Internet is one of the reasons causing information disparity.

At present, protection and development of the language is announced as the language policy of the European Union. The focal way to achieve success in this field is mastering more than one foreign language.

The main threats to the language are as follows:

-inclusion of foreign words into the spoken and written language, i.e. the use of foreign words in the advertisings, names of commercial enterprises, informal and professional communication, mass media texts, official speeches of social and political figures, as well as, in the speech of TV presenters, scientific literature, and so on;

-criminalization of the speech, i.e. excessive use of criminal slangs in the speech, which is typical for representatives of the criminal world; Both the youngsters, as well as representatives of the older generation, sometimes officials use these slangs, mainly during online communication;

-literacy rate of the population and the decline of the culture of speech, which is related to the decline in the teaching of the native language.

All above-mentioned problems cause a collapse of national unity of the country, its moral culture and intellectual potential, in this case, one of the main issues of national security is to ensure the safety of the language.

Language policy plays the key role in the protection of the language from emerging threats. This policy is defined as a set of practical measures and ideological principles on solving the language problems in the society and country.

Thus, the safety of the language system is a multidimensional and complex notion, the features of which are defined by the social-linguistic situation in the country.

\section{State-of-the-art and usage of the world's languages}

Due to the globalization process, more than half of nearly six thousand languages are in danger of extinction [3]. Initially, the languages of small the peoples are under the risk. Therefore, UNESCO 
tries to monitor the general situation of endangered languages and to examine the ways to eliminate these problems. Because, even the least-used language, no doubt, is a manifestation of a particular culture. International Mother Language Day has been observed since 2000 initiated by UNESCO on 21 February to draw the world's attention to this problem, as well as to take the necessary measures.

Note that, Azerbaijan joined this initiative, as well. The worldwide annual observance aims at promoting awareness of linguistic and cultural diversity.

In this regard, a number of documents Universal Declaration on Cultural Diversity (2001) [4], Convention for the Safeguarding of the Intangible Cultural Heritage (2003) [5], and the Recommendation concerning the Promotion and Use of Multilingual and Universal Access to Cyberspace (2003) [6] have been adopted.

In general, the languages are distinguished into several groups according to its vitality. And what are the criteria and principles according to which the lost languages are identified?

In 2002-2003 UNESCO referred to the International Group of Linguists to develop the methodology to define the vitality of the languages. The experts specialized in endangered languages worked out the concept of the document "Language Vitality and Endangerment". The following 9 factors have been set to assess the threat to this or other language [7]:

1. Intergenerational language transmission;

2. Absolute number of speakers;

3. Proportion of speakers within the total population;

4. Availability of materials for language education and literacy;

5. Response to new domains and media;

6. Type and quality of documentation;

7. Governmental and institutional language attitudes and policies, including official status and use;

8. Shifts in domains of language use;

9. Community members' attitudes toward their own language.

No criteria separately allow judging about the status of any language. The transmission of the language from generation to generation is a key factor, and no other criteria affect the protection of the language so much. Basing on the above-mentioned, the experts distinguished six groups of all available languages (Table 1). All of these have been included in the Language Vitality and Endangerment adopted by UNESCO in 2003 [8].

Currently, 2473 out the world's languages are included into the last five groups. A more affordable study and solution of this problem is the Atlas of the world's languages in danger (Figure 1). The Atlas provides the regions, where endangered languages exist. For example, the map shows all of 2473 languages, and geographical position of each group can be viewed separately through the project [9].

Northern part of Australia, central South America, Oklahoma and the south-west regions of the United States, north-western region of the Pacific Ocean and Eastern Siberia are the regions, where the languages are falling out of use [10].

One of the measures taken to solve these problems is to support and promote the development of the multilingualism in order to protect the cultural and linguistic diversity in the virtual space [11].

In general, any nation completely destroyed by natural disasters, non-use of native language in the education system for this or other reasons, the use of other languages, acceleration of the transition process from multilingual to monolingual communication in the virtual space as a result of the development of ICT and Internet, and other reasons pose the threats to the existence of languages. 
Language Vitality and Endangerment

\begin{tabular}{|c|c|c|}
\hline $\begin{array}{c}\text { Degree of } \\
\text { endangerment }\end{array}$ & Grade & Intergenerational Language Transmission \\
\hline Safe & 5 & $\begin{array}{l}\text { language is spoken by all generations; intergenerational transmission } \\
\text { is uninterrupted }\end{array}$ \\
\hline vulnerable & 4 & $\begin{array}{c}\text { most children speak the language, but it may be restricted to certain } \\
\text { domains (e.g., home) }\end{array}$ \\
\hline $\begin{array}{l}\text { Definitely } \\
\text { endangered }\end{array}$ & 3 & children no longer learn the language as mother tongue in the home \\
\hline $\begin{array}{c}\text { Severely } \\
\text { endangered }\end{array}$ & 2 & $\begin{array}{l}\text { language is spoken by grandparents and older generations; while the } \\
\text { parent generation may understand it, they do not speak it to children } \\
\text { or among themselves }\end{array}$ \\
\hline $\begin{array}{c}\text { Critically } \\
\text { endangered }\end{array}$ & 1 & $\begin{array}{l}\text { the youngest speakers are grandparents and older, and they speak the } \\
\text { language partially and infrequently }\end{array}$ \\
\hline Extinct & 0 & there are no speakers left \\
\hline
\end{tabular}

Presently, the top 10 languages most commonly used on the Internet include English $26.0 \%$, Chinese 21.5\%, Spanish 7.5\%, Arabic 4.8\%, Portuguese 4.0\%, Japanese 3.5\%, Russian 3.2\%, Malay $2.9 \%$, French $2.8 \%$, German $2.6 \%$ (Table 2). Other languages used on the Internet amounts $21.2 \%$ [12]. In other words, some languages widely used during this process have even greater areal, and become a major means of communication among the world's peoples, dislodging other languages.

In the XXI century, United Nations General Assembly has declared 2008 the International Year of Languages to combat these problems in the virtual space, and to take cost-effective and urgent measures to address them [13].

\section{State care for the protection of the Azerbaijani language}

What projects are currently being implemented for the preservation and development of the Azerbaijani language? A number of steps have been taken for the development of our language. National leader Heydar Aliyev always paid special attention to mother tongue and signed important documents in this regard: "Decree on improving the use of the state language" (January 12, 2003) [14], "Order on the approval of organizing the State Language Commission of the Republic of Azerbaijan" (July 4, 2001) [15], "Decree on the establishment of the Day of the Azerbaijani alphabet and Azerbaijani language" (August 9, 2001) [16]. At the same time, the Law on the state language of the Republic of Azerbaijan (September 2002) entered into force with the decree signed by Heydar Aliyev dated January 2, 2003 [17], which clearly defines the main tasks in the care of the mother tongue.

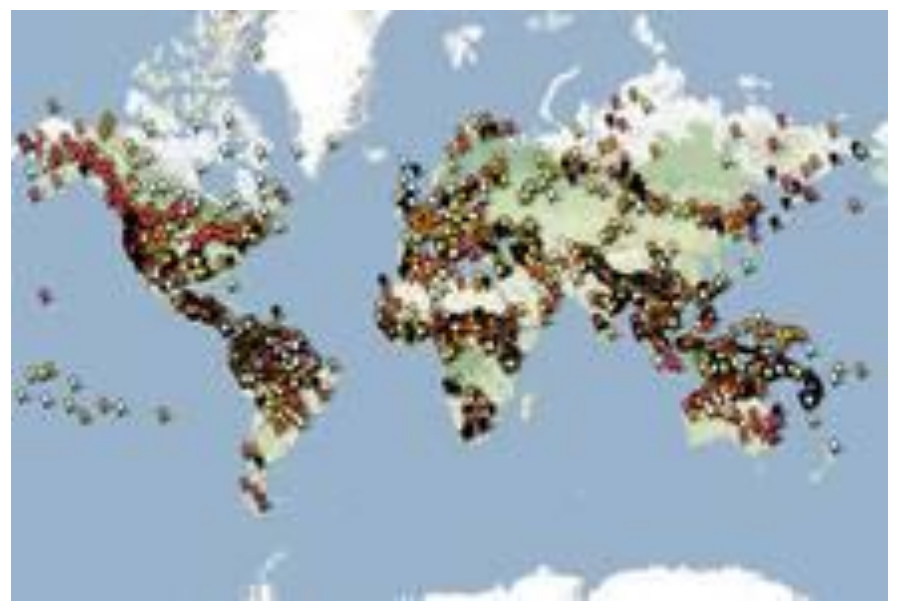

Figure 1. Atlas of the World's Languages in Danger 
Top Ten Languages Used in the Web (June 30, 2015)

Table 2.

\begin{tabular}{|c|c|c|c|c|c|}
\hline $\begin{array}{c}\text { Top ten } \\
\text { languages in } \\
\text { the Internet }\end{array}$ & $\begin{array}{c}\text { Internet users } \\
\text { by language }\end{array}$ & $\begin{array}{c}\text { Internet } \\
\text { penetration } \\
(\% \\
\text { population) }\end{array}$ & $\begin{array}{c}\text { Users } \\
\text { growth in } \\
\text { Internet }\end{array}$ & $\begin{array}{c}\text { Internet users } \\
\% \text { of World } \\
\text { Total } \\
\text { (participation) }\end{array}$ & $\begin{array}{c}\text { World } \\
\text { population for } \\
\text { this language } \\
(2015 \\
\text { Estimate) }\end{array}$ \\
\hline English & $851,623,892$ & $60.9 \%$ & $505.0 \%$ & $26.0 \%$ & $1,398,277,986$ \\
\hline Chinese & $704,484,396$ & $50.4 \%$ & $2,080.9 \%$ & $21.5 \%$ & $1,398,335,970$ \\
\hline Spanish & $245,150,733$ & $55.5 \%$ & $1,248.4 \%$ & $7.5 \%$ & $441,778,696$ \\
\hline Arabic & $155,595,439$ & $41.5 \%$ & $6,091.9 \%$ & $4.8 \%$ & $375,241,253$ \\
\hline Portuguese & $131,615,190$ & $50.0 \%$ & $1,637.3 \%$ & $4.0 \%$ & $263,260,385$ \\
\hline Japanese & $114,963,827$ & $90.6 \%$ & $144.2 \%$ & $3.5 \%$ & $126,919,659$ \\
\hline Russian & $103,147,691$ & $70.5 \%$ & $3,227.3 \%$ & $3.2 \%$ & $146,267,288$ \\
\hline Malay & $93,915,747$ & $32.7 \%$ & $1,539.0 \%$ & $2.9 \%$ & $286,937,168$ \\
\hline French & $92,265,199$ & $23.9 \%$ & $669.0 \%$ & $2.8 \%$ & $385,389,434$ \\
\hline German & $83,738,911$ & $87.8 \%$ & $204.3 \%$ & $2.6 \%$ & $95,324,471$ \\
\hline $\begin{array}{c}\text { TOP 10 } \\
\text { LANGUAGES }\end{array}$ & $2,576,501,025$ & $52.4 \%$ & $768.2 \%$ & $78.8 \%$ & $4,917,732,310$ \\
\hline $\begin{array}{c}\text { Rest of the } \\
\text { Languages }\end{array}$ & $693,989,559$ & $29.6 \%$ & $980.6 \%$ & $21.2 \%$ & $2,342,888,808$ \\
\hline $\begin{array}{c}\text { WORLD } \\
\text { TOTAL }\end{array}$ & $3,270,490,584$ & $45.0 \%$ & $806.0 \%$ & $100.0 \%$ & $7,260,621,118$ \\
\hline
\end{tabular}

As a continuation of the work carried out for the protection of Azerbaijani language the President of the Republic of Azerbaijan Ilham Aliyev signed the decree on publishing of mass media in Latin (January 12, 2004). The decree obliged new textbooks, scientific publications, dictionaries and fictions to be published in Latin alphabet in Azerbaijani language. This document is of great importance for the further enrichment of the national literary language and considerable development of linguistics [18]. Besides, the president signed a decree dated May 23, 2012 on the development of "The State Program on the use of Azerbaijani language in the context of globalization, in accordance with the requirements of the times and the development of linguists in the country" [19]. The decree reviews historical evolution and development stages of the Azerbaijani language from the scientific and historical point of view, and highlights the problems in this field in terms of globalization, and the measures to be taken. The document focuses on the concerns about the lack of resources in Azerbaijani language on the Internet, and the lack of electronic and interactive textbooks, inappropriate workbooks for the foreigners learning the Azerbaijani language, and the existence of significant gap in the field of linguistics in the country due to the isolation of the Azerbaijani linguistics from the processes going on in the world science community during the Soviet period. The State Program on the use of Azerbaijani language in the context of globalization, in accordance with the requirements of the times and the development of linguists in the country approved by the Decree of the President dated April 9, 2013, has played an important role in the successful implementation of the language policy in the country. The program implies the implementation of the necessary measures during 2013-2020 for the protection of the purity and enrichment of the mother tongue, which is the mirror of morality. The goal of the program is to increase state support for the use of Azerbaijani language in accordance with the requirements of the times in the context of globalization, and to improve linguistics research in the country substantially. At the same time, the document involves the consolidation of the creative efforts directed to the development of 
fundamental and applied studies in the fields of linguistics, and the coordination of linguistics with the urgent problems of the modern society.

The presence of state support for the introduction and development of the language, a wide areal of use of the Azerbaijani language partially reduces such threats. In addition, the Azerbaijani language is broadening in the virtual space.

\section{Existing problems in the field of terminology in Azerbaijan and their solutions}

Preserving our language, ensuring its purity and development are the duties and important mission of the terminological activity. So, previously, the terminological environment was controlled both by the state and society. It was due to several reasons. The number of publications translated from foreign languages into Azerbaijani language was not so much, and the translation process was strictly controlled, and the publications across the country were examined at various levels. On the other hand, the mass media (television, radio, etc.) materials had to meet terminological requirements, when the use of foreign words was too incorrect [20].

Recently, as the result of the prevalence of foreign media, most importantly, the rapid penetration of the Internet in various spheres of society, the use of materials in vast areas of knowledge it became very difficult to control the Azerbaijani terminological environment. In such circumstances, it is important to protect terminological base of the language from the foreign words, to develop an online resource available for all Azerbaijanis of the world, to attract the general public to create new terms through interactive forums, and etc.

The direct impact of the globalization, which penetrated many spheres of society, on the language is due to its lexical level. One of the core and most active sections of the vocabulary, i.e. terminology is changed and updated with the scientific and technological progress and globalization. Integration into the international and European community has an impact on all levels of the language, as well as on the terminology [21].

In recent years, enrichment of the language becomes a natural process. There is no language in the world enriched without borrowed words. Prevention of this process, in fact, is to be drawn back from the development. Nevertheless, the inclusion of needless words into the language should not be allowed. And the borrowed words should adapt the grammatical rules of the language, and define the notion precisely.

In modern times, the terminology of the world's languages, except English, is unified. This process is underway especially in the information and telecommunications sector. Therefore, regardless of the scientific and technical, socio-political or mass media terminology, the system of terminology faces the problem of "to be or not to be" [22].

In the best-case scientific informatics and socio-political terminology refers to the international terms, in the worst case, larger neighbors or traditional languages are referred.

What steps should be taken by the government to avoid the dominance of the languages on the native language, and to transform the national language into the language of the exchange in all spheres of scientific and socio-political life?

Is it possible to maintain the feature of language selection of the nations in terms of economic globalization of information facilities and technical capabilities?

And shall we strive for the independence of language selection, or accept the realities of the current globalization process, and the unification of scientific, technical, social and political terminology in all languages?

English and some other languages are considered to be international language of communication and exchange of scientific information. Even the languages of developed countries in Europe and Asia, as French, German, Japanese, and Chinese can not compete with English. Thus, there are two ways to solve the problem of choosing the term correspondence. The first direction brings the international term to the national language without changes. The second direction replaces the international term with the term in the national language fully. Both 
cases cause own dangers. Relevant authorities of Azerbaijan, as well as research institutions of ANAS try to resolve the selection of the correspondence of the foreign term in the Azerbaijani language. International terms can be used in scientific texts; however, in broader use their correspondence shall be preferred.

We can conclude that the languages not capable to provide the development of scientific and informative ideas reflecting the latest scientific achievements shall use the international language of communication. In the modern world, it is a reality, though it is not accepted.

At present, information technologies are the most efficient tool to receive any information. In this regard, Internet resources should be enriched, new websites should be established for the protection, development and promotion of the language, culture, literature, and music.

Wikipedia, launched in 2001, now incorporates about millions of information resource. The portal stores 35 million articles in 286 languages and 25 million pictures, audio and video materials (Common warehouse stores 25 million media file). The number of registered users in the virtual encyclopedia reaches 60 million, while the total number of the website users is 300 million. Over 4 billion people visit the portal a month from all over the world [23].

Today, more than 50 million Azerbaijanis living in different countries of the world should take practical steps to protect, develop our mother tongue, and work actively for its recognition all over the world.

\section{Conclusion}

As we mentioned earlier, our language was protected by the closed information environment. Now this environment is open, and the virtual space is integrating. It is very difficult to protect and develop the language in terms of open society. To protect the language, its vocabulary from all these factors, and to minimize the impact of negative factors, which prevent its natural development, is of great importance.

Given these realities, to resolve the introduction, development and other problems of the language it is recommended:

- to conduct fundamental large-scale research, analyzes and investigations in this regard;

- to ban foreign-language titles of the restaurants, shops and other facilities in the cities, villages and towns of Azerbaijan;

- to ensure the monitoring mechanisms for the preservation and enrichment of literary norms of the language in mass media, especially television channels;

- to develop the system to monitor the status of expansion and development of introducing the Azerbaijani language;

- to coordinate various organizations dealing with different problems of language and linguistics;

- to prepare proposals to improve the state language policy;

- to prepare textbooks and electronic resources for the foreign learners of the language;

- to develop appropriate legal documents;

- to develop new Web2-based websites for the use of language development, enhancement and promotion;

- to develop terminology websites in different fields of science and technology.

\section{References}

1. Dolgova T.V. Impact of globalization on national languages and internationalization of the terms, 17_Dolgova_-_Влияние_процессов_глобализации_на_национальные_языки.pdf

2. Gritsenko E.S. Language and security in the context of globalization. Scientific journal Power, M., 2011, Vol. 11, p.p. 9-11.

3. Dorzhieva M. $80 \%$ of the world's languages are in real danger of extinction, Epoch, 2013, http: //www.epochtimes.ru/content/view/80047/5/ 
4. Universal Declaration on Cultural Diversity.Adopted by the 31st Session of the General Conference of UNESCO, Paris, 2 November 2001, 44 p.p.

5. Convention for the safeguarding of the intangible cultural heritage, Paris, 17 October 2003, http://www.unesdoc.unesco.org/images/0013/001325/132540e.pdf.

6. Recommendation concerning the Promotion and Use of Multilingualism and Universal Access to Cyberspace, The General Conference, Paris, 15 October 2003, http://www.portal.unesco.org/

7. Methodology for assessing language vitality and endangerment. http://www.unesco.org/new/ru/culture/themes/endangered-languages/language-vitality/

8. UNESCO Ad Hoc Expert Group on Endangered Languages. Language Vitality and Endangerment. Paris, 10-12 March 2003, http://www.unesco.org/new/fileadmin/MULTIMEDIA/HQ/CLT/pdf/Language_vitality_and _endangerment_EN.pdf

9. UNESCO Interactive Atlas of the World's Languages in Danger,http://www.unesco.org/languages-atlas/index.php?hl=en\&page=atlasmap

10. The world is losing languages, http://www.akzia.ru

11. Recommendations concerning the Promotion and Use of Multilingualism and Universal Access to Cyberspace, http://www.unesdoc.unesco.org/images/0013/001331/133171r.pdf

12. http://www.internetworldstats.com

13. Message from Mr.Koïchiro Matsuura, Director-General of UNESCO, on the occasion of International Mother Language Day, 21 February, 2008,

14. http://www.unesdoc.unesco.org/images/0015/001568/156825e.pdf

15. Decree of the President of the Republic of Azerbaijan on improving the use of the state language, Baku, June 18, 2001, http://www.president.az

16. Order of the President of the Republic of Azerbaijan on the approval of organizing the State Language Commission of the Republic of Azerbaijan, Baku, July 4, 2001, http://www.president.az

17. Decree on the establishment of the Day of the Azerbaijani alphabet and Azerbaijani language, Baku, 9 August 2001, http://www.president.az

18. Decree on improving the Law on the state language, Baku, Jan. 2, 2003, http://www.president.az

19. Decree of the President of the Republic of Azerbaijan on publishing of mass media in Latin, Baku, Jan. 12, 2004, http://www.president.az

20. Decree of the President of the Republic of Azerbaijan on the State Program on the use of Azerbaijani language in the context of globalization, in accordance with the requirements of the times and the development of linguists in the country, Baku, May 23, 2012, http://www.president.az

21. Alguliyev R.M., Gurbanova A.M. Azerbaijani language problems and solutions in virtual space. Terminology issues, Baku, 2009, p.p. 11-18.

22. Sadigova S.A. Mother tongue is the mirror of the national existence, http://www.xalqqazeti.com

23. Kuranbekov A. Problems of formation of scientific and technical terminology in the modern Persian language // Philology issues, 2003, Vol. 2 (14), p.p. 16-18.

24. http://www.wikipedia.org 